BIS WORKING PAPERS

No. 75 - August 1999

\title{
A NOTE ON THE GORDON GROWTH MODEL WITH NONSTATIONARY DIVIDEND GROWTH
}

by

Henri Pagès

BANK FOR INTERNATIONAL SETTLEMENTS

Monetary and Economic Department

Basel, Switzerland 
BIS Working Papers are written by members of the Monetary and Economic Department of the Bank for International Settlements, and from time to time by other economists, and are published by the Bank. The papers are on subjects of topical interest and are technical in character. The views expressed in them are those of their authors and not necessarily the views of the BIS.

Copies of publications are available from:

Bank for International Settlements

Information, Press \& Library Services

$\mathrm{CH}-4002$ Basel, Switzerland

Fax: +41 61 / 2809100 and +4161/2808100

This publication is available on the BIS website (www.bis.org).

(C) Bank for International Settlements 1999.

All rights reserved. Brief excerpts may be reproduced or translated provided the source is stated. 
BIS WORKING PAPERS

No. 75 - August 1999

\title{
A NOTE ON THE GORDON GROWTH MODEL WITH NONSTATIONARY DIVIDEND GROWTH
}

by

Henri Pagès *

\begin{abstract}
Researchers have sometimes argued that the recent ascent in stock prices could be explained in some measure by changes in expectations about long-run future dividend growth. For example, Barsky and De Long (1993) argue that a small random walk component in the growth rate of dividends, when extrapolated into the future, is capable of reproducing the large swings in US stock prices over the period 1880-1990. I show that the hypothesis of a nonstationary permanent growth rate of dividends is inconsistent with the Gordon growth model.
\end{abstract}

* I thank J Amato, P Andersen, J Bisignano, S Gerlach, G Sutton and K Tsatsaronis for many valuable comments and suggestions. I also thank, without implicating, M Jeanblanc for pointing out an error in a previous draft. 



\section{Contents}

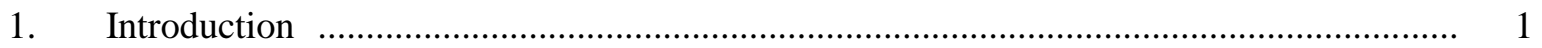

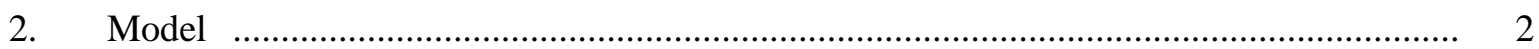

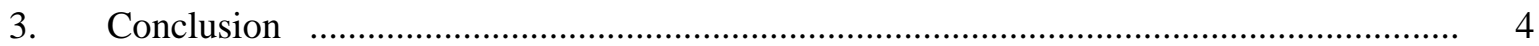

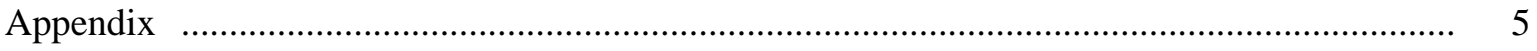

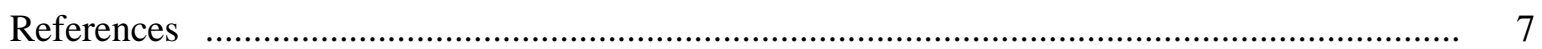





\section{Introduction}

To explain long-run swings in the US stock market, Barsky and De Long (1993) - hereafter BD computed "warranted" stock prices on the assumption that investors extrapolate a long distributed lag of realised dividend growth rates into the future. Their approach combines the standard Gordon model of stock price determination with a model of dividend changes characterised by a time-varying, albeit small, persistent component. The thrust of their argument is that small but permanent shocks to dividend growth rates may have a dramatic impact on stock prices. This goes some way towards explaining the documented "overreaction" of asset prices to long swings in dividends, thus restoring the power of the conventional present-value model.

In contrast to Mankiw, Romer and Shapiro $(1985,1991)$ and Kleidon (1986), who emphasise that the $\log$ dividend process is close to a random walk, BD postulate an environment in which it is the growth rate of dividends that contains a random walk. The two approaches are distinct, since in the former case an innovation in the growth rate of dividends is assumed to be temporary, whereas in the latter it is expected to persist indefinitely. Despite this difference, BD predicate their analysis on the Gordon valuation formula, a variant of the present-value model which obtains when the rate of dividend growth is constant.

BD's methodology has been followed by other researchers. Carlson and Sargent (1998), for instance, consider a similar setup where the growth of earnings replaces that of dividends. A reason for this may be that it has an important bearing on policy. Indeed, if investors expect part of the recent rise in dividends to be permanently incorporated in future dividend growth, the recent ascent in stock prices might be deemed appropriate. By contrast, stationary models of dividend growth rates would generally fail to conclude that stocks are rationally priced, given current trends of dividend payments.

Applying a formula which does not hold when the growth rate of dividends is nonstationary is logically inconsistent. Indeed, BD recognise (p. 299) that the formula

"does not hold exactly in a stochastic model for the dividend process given by (3): [it] does not allow prices today to be influenced by investors' knowledge that they will be revising their estimate of $g$ in the future."

They continue:

"But for simplicity we ignore these higher-order corrections here and use [it] as our formula for the log of warranted stock index price."

However, the situation is worse than BD acknowledge. In their model, outlined below, the sum of expected discounted dividends fails to converge, and Gordon's valuation formula is not applicable. 


\section{Model}

With a constant required rate of return, the standard version of the present-value model is $P_{t}=E_{t}\left[\sum_{j=1}^{\infty}(1+r)^{-j} D_{t+j}\right]$, where $P_{t}$ is the real stock price, $D_{t+j}$ the real dividend paid at time $t+j$ and $r$ the real rate of return (or discount rate). It is useful to rewrite the formula in terms of future dividend growth rates as:

$$
P_{t}=D_{t} E_{t}\left[\sum_{j=1}^{\infty} \exp \left\{-j\left(\rho-g_{t}^{j}\right)\right\}\right]
$$

where $g_{t}^{j}=\left(d_{t+j}-d_{t}\right) / j$ denotes the average dividend growth rate between $t$ and $t+j, d_{t}$ is the log of dividends, and the discount rate has been renormalised as $\rho=\ln (1+r)$. In the special case of a constant growth rate with $\exp g_{t}^{j}=1+g$, formula (1) simplifies to:

$$
P_{t}=D_{t} \frac{1+g}{r-g}
$$

which is the well-known Gordon growth model (1962).

If the dividend growth rate varies over time, (2) is not directly applicable. However, one may wish to consider (2) as an approximation if dividends are expected to grow at a constant rate in the future, i.e. if $E g_{t}^{j}=g_{t}$ for all $j$. As an extreme case, an investor certain that the mean dividend growth rate is a fixed but unknown parameter of the economy could extrapolate it from period to period and substitute the resulting estimate $g_{t}$ for $g$ in the Gordon formula. However, Jensen's inequality shows that substituting expected for realised growth in (1) induces a downward bias. The empirical relevance of that bias depends in turn on the specification of the underlying process governing dividends.

It is important at this point to understand intuitively the complications that arise when the dividend process is stochastic. This assumption implies that the average growth of dividends $g_{t}^{j}$ from $t$ to $t+j$ may be greater than $\rho$ with positive probability, rendering the exponential in (1) greater than unity. If this occurs only finitely many times in the future, there is no convergence problem and $P_{t}$ in (1) is well-defined. If not, the probability that this happens must decrease sufficiently fast as $j$ increases. Failing this, $P_{t}$ would not be well-defined, as more and more terms would contribute in a nonnegligible way to the infinite sum. ${ }^{1}$

1 Note that $E_{t}\left[\exp \left\{-j\left(\rho-g_{t}^{j}\right)\right\}\right] \geq E_{t}\left[\exp \left\{-j\left(\rho-g_{t}^{j}\right)\right\} ;\left\{g_{t}^{j} \geq \rho\right\}\right] \geq E_{t}\left[1 ;\left\{g_{t}^{j} \geq \rho\right\}\right]=\operatorname{Prob}\left(g_{t}^{j} \geq \rho\right)$. A necessary condition for convergence is thus that Prob $\left(g_{t}^{j} \geq \rho\right) \rightarrow 0$ as $\mathrm{j} \rightarrow 0$. 
Assume, for example, that $\Delta d_{t}$ contains a unit root. As the length of the horizon $j$ increases, the range of values taken by future growth rates will increase and so will the variance of their arithmetic mean $g_{t}^{j}$. This holds even though, as of time $t, g_{t}^{j}$ itself has a constant expectation equal to $g_{t}$. With the tails of the distribution growing fatter around its fixed mean, the probability that $g_{t}^{j}$ overshoots the constant discount rate $\rho$ keeps increasing and drives the stock price to infinity.

Returning to BD's model, one notes that the specification of their underlying dividend process relies on two assumptions. First, dividend growth is modelled as the sum of a white-noise innovation, $\varepsilon_{t}$, and a permanent growth component $g_{t-1}$ :

$$
\Delta d_{t}=g_{t-1}+\varepsilon_{t}
$$

Second, the permanent growth component $g_{t}$ is revised each period by a small fraction of current dividend changes:

$$
g_{t}=\theta g_{t-1}+(1-\theta) \Delta d_{t}
$$

where $\theta$ is a parameter close to one. In other words, the permanent growth component is a geometric average of past dividend changes, with rate of decay $1-\theta$. Equations (3-4) are identical to (3-4) in BD. ${ }^{2}$ The two assumptions taken together imply that $g_{t}=g_{t-1}+(1-\theta) \varepsilon_{t}$ is itself a random walk. By (3), this implies that $\Delta d_{t}$ contains a unit root. As argued above, it follows that the stock price is infinite. A formal proof is given in the Appendix.

It is the fast rate at which the volatility of future average growth increases that prevents the infinite sum defining present value in (1) from converging. The following back-of-the-envelope calculation casts light on this issue. We need the following property of random variables: if $\ln x$ is normal with mean $\mu$ and variance $\sigma^{2}$, then $\ln E(x)=\mu+\sigma^{2} / 2$. Here, $g_{t}^{j}$ tends to a conditionally normal distribution, with mean $g_{t}$ and variance $j \sigma^{2}$, where $\sigma^{2}$ is an empirically "small" number depending on the value of $\theta$. Accordingly, the $j$ th term in (1) is approximately log-normal for large $j$, with mean $\exp \left\{-j\left(\rho-g_{t}\right)+j^{3} \sigma^{2} / 2\right\}$. We see that, when $\mathrm{j} \rightarrow \infty$, the variance term in $j^{3}$ causes the expectation to explode. (The argument is only heuristic, since $g_{t}^{j}$ does not have a well-defined limit distribution.)

2 In a footnote BD point out that, instead of treating (2) as an approximation to the pricing rule, one could treat (3-4) as an approximation to the dividend process if permanent growth is governed by the following stochastic differential equation:

$$
d g_{t}=-\frac{(1-\theta)^{2} \sigma_{\varepsilon}^{2}}{r-g_{t}} d t+(1-\theta) \sigma_{\varepsilon} d W_{t}
$$

However, Ito's formula shows that $y_{t}=\left(r-g_{t}\right) / \sigma_{\varepsilon}(1-\theta)$ satisfies:

$$
d y_{t}=\frac{d t}{y_{t}}-d W_{t}
$$

and is thus a Bessel process of dimension 3. It follows that $y_{t} \rightarrow \infty$ as $t \rightarrow \infty$. The fact that growth rates become arbitrarily large and negative raises doubts about the relevance of this formulation. 


\section{Conclusion}

This note has investigated whether the assumption of a "permanent" growth rate of dividends is consistent with a constant discount rate. It was found that the infinite sum defining present-value diverges when the dividend growth rate $g_{t}$ has a random walk component. Of course, it may be possible to restore convergence in the present-value model by assuming that the forcing process for dividends contains a very persistent but stationary autoregressive root instead of an exact unit root. The inferences above, however, imply that as this root tends to one, the associated stock price tends to infinity and cannot be approximated by the Gordon valuation formula. On the other hand, a lower autoregressive root would mean that $g_{t}$ is less correlated with past dividend growth rates. This runs up against the very intuition of the model, which views past dividend growth rates as the main driving force behind revisions in expected future dividend growth. Whether the model retains considerable power under the present context remains uncertain, since one cannot embed the assumption of nonstationarity in dividend growth in the present-value model without considering its long-run theoretical consequences.

This leaves us with the issue of which assumption of the Gordon model should be relaxed for the present-value model with nonstationary dividend growth to remain meaningful. One way to restore convergence might be to drop the assumption of a constant discount rate and derive instead the required rate of return endogenously within an equilibrium asset pricing model. I have not been able to find a simple model, with standard specification of preferences, that would be consistent with nonstationarity in dividends. How to value equity in the present context seems to remain an open question. 


\section{Annex}

\section{Proposition 1}

When $j \rightarrow \infty$, the variable $j^{-1 / 2} g_{t}^{j}$ converges in distribution to a normal variable with mean 0 and variance $(1-\theta)^{2} \sigma_{\varepsilon}^{2} / 3$.

Proof. Let $X_{n}^{u}=\sqrt{u} \Delta d_{t+n}$ for some small $u>0$. From (3-4), one gets the scalar difference equation

$$
X_{n}^{u}=X_{n-1}^{u}+\sqrt{u}\left(\varepsilon_{t+n}-\theta \varepsilon_{t+n-1}\right)
$$

It is readily verified that the spectrum at 0 of the innovation $\varepsilon_{t+n}-\theta \varepsilon_{t+n-1}$, defined as the infinite sum of its autocovariances at all leads and lags, is $(1-\theta)^{2} \sigma_{\varepsilon}^{2}$. It follows from weak convergence arguments that the process $X_{n}^{u}$ converges weakly to the process $x=(1-\theta) \sigma_{\varepsilon} w$, where $w$ is a standard Brownian motion, as $u \rightarrow 0$; e.g. Kushner (1984), pp. 91-3. In particular, choosing $u j=1$, one sees that:

$$
\begin{aligned}
j^{-1 / 2} g_{t}^{j} & =j^{-3 / 2}\left(d_{t+j}-d_{t}\right) \\
& =u \sum_{n=1}^{j} X_{n}^{\varepsilon} \\
& \Rightarrow \int_{0}^{1} x_{s} d s=(1-\theta) \sigma_{\varepsilon} \int_{0}^{1} w_{s} d s
\end{aligned}
$$

The variable $\int_{0}^{1} w_{s}$ has mean zero and variance

$$
\begin{aligned}
E \int_{0}^{1} \int_{0}^{1} w_{s} w_{t} d s d t & =\int_{0}^{1} \int_{0}^{1} s \wedge t d s d t \\
& =\int_{0}^{1}\left[\int_{0}^{t} s d s+\int_{t}^{1} t d s\right] d t \\
& =\int_{0}^{1}\left[\frac{t^{2}}{2}+t(1-t)\right] d t=1 / 3
\end{aligned}
$$

hence the result.

To see that the standard present-value model breaks down, consider the jth element in the infinite sum of expected future dividends. If $U$ is a random variable with the limit distribution of proposition 1 , and $\varphi$ some strictly positive, bounded continuous function ${ }^{3}$ such that $\varphi(x) \leq \exp \left\{-j \rho+j^{3 / 2} x\right\}$ for all $j$, one has:

3 For example, the envelope $\varphi(x)=1_{\{x>0\}} \exp \left\{-\frac{4 \rho^{3}}{27 x^{2}}\right\}$ of all functions $\varphi_{\alpha}(x)=\exp \left\{-\alpha \rho+\alpha^{3 / 2} x\right\}$ for $\alpha>0$ 


$$
\begin{aligned}
E\left[(1+r)^{-j} \frac{D_{t+j}}{D_{t}}\right] & =E\left[\exp \left\{-j\left(\rho-g_{t}^{j}\right)\right\}\right] \\
& =E\left[\varphi\left(j^{-1 / 2} g_{t}^{j}\right)\right] \\
& =E[\varphi(U)]
\end{aligned}
$$

a strictly positive number. Since discounted expected future dividends are bounded away from 0 , their infinite sum defining present value diverges. 


\section{References}

Barsky, Robert B and Bradford J De Long (1993): "Why Does the Stock Market Fluctuate?" The Quarterly Journal of Economics, vol. CVIII, pp. 291-311.

Carlson, John B and Kevin H Sargent (1998): "The Recent Ascent of Stock Prices: Can It Be Explained by Earnings Growth or Other Fundamentals?" Cleveland Federal Review, pp. 2-12.

Gordon, M (1962): The Investment, Financing, and Valuation of the Corporation. Irwin, Homewood, IL.

Kleidon, Allen (1981): "Variance Bounds Tests and Stock Price Valuation Models". Journal of Political Economy, vol. XCIX, pp. 555-74.

Kushner, Harold J (1984): Approximation and Weak Convergence Methods for Random Processes. MIT Press, Cambridge, MA.

Mankiw, N Gregory, David Romer and Matthew Shapiro (1985): "Unbiased Reexamination of Stock Market Volatility". Journal of Finance, vol. XL, June, pp. 677-87.

Mankiw, N Gregory, David Romer and Matthew Shapiro (1991): "Stock Market Forecastability and Volatility: A Statistical Appraisal”. Review of Economic Studies, vol. LVIII, May, pp. 455-77. 



\section{Recent BIS Working Papers}

No.

59

November 1998

60

November 1998

61

November 1998

62

March 1999

63

March 1999

64

March 1999

65

April 1999

66

April 1999

67

May 1999

68

May 1999

69

June 1999

70

June 1999

71

June 1999

72

August 1999

73

August 1999

74

August 1999
Title

Portfolio selection using fuzzy decision theory

Output gap uncertainty: does it matter for the Taylor rule?

Foreign direct investment and employment in the industrial countries

The pricing of bank lending and borrowing: evidence from the federal funds market

Microeconomic inventory adjustment and aggregate dynamics

Precarious credit equilibria: reflections on the Asian financial crisis

Higher profits and lower capital prices: is factor allocation optimal?

Evolving international financial markets: some implications for central banks

The cyclical sensitivity of seasonality in US employment

The evolution and determinants of emerging market credit spreads in the $1990 \mathrm{~s}$

Credit channels and consumption in Europe: empirical evidence

Interbank exposures: quantifying the risk of contagion

The term structure of announcement effects

Reserve currency allocation: an alternative methodology

The Taylor rule and interest rates in the EMU area: a note

The dollar - mark axis
Author

Srichander

Ramaswamy

Frank Smets

P S Andersen and $\mathrm{P}$ Hainaut

Craig H Furfine

Jonathan McCarthy and Egon Zakrajšek

Joseph Bisignano

P S Andersen, M Klau and $\mathrm{E}$ Yndgaard

William R White

Spencer Krane and William Wascher

Steven B Kamin and Karsten von Kleist

Gabe de Bondt

Craig H Furfine

Michael J Fleming and Eli M Remolona

Srichander Ramaswamy

Stefan Gerlach and Gert Schnabel

Gabriele Galati 